\title{
Inhibition of multiple ovulation in hypophysectomized hens treated with gonadotrophins
}

\author{
K. Ogawa, H. Tojo and Y. Kajimoto \\ Laboratory of Animal Reproduction, Faculty of Agriculture, Kagoshima University, \\ Kagoshima, Japan
}

\begin{abstract}
Summary. Administration of PMSG or FSH to hypophysectomized hens prevented the multiple ovulation ( $2-3$ ova) induced by an OIH. Inhibition of multiple ovulation did not occur when FSH was injected $\frac{1}{2}-2 \mathrm{hr}$ before the OIH injection. The results are believed to support the theory that withdrawal of FSH stimulation sensitizes a follicle to the OIH in the normal hen.
\end{abstract}

Multiple ovulation is easily induced by exogenous $\mathrm{LH}$ in mammals in which a number of follicles have been stimulated to develop by treatment with FSH. However, in the intact hen, even if LH is administered in a broad range of dosages, it is impossible to induce more than one ovulation, which always occurs from the largest mature follicle. Opel \& Nalbandov (1961) reported that a double ovulation could be induced in hypophysectomized laying hens by a single i.v. injection of mammalian LH 3-15 hr after the operation. From this finding, Nalbandov (1961) proposed that the ability of LH to induce a follicle to ovulate is facilitated by prior withdrawal of FSH stimulation.

The present study was carried out to examine this theory.

Single-comb White Leghorn pullets, aged 8-10 months, were caged singly in a standard light regimen of $14 \mathrm{hr}$ light/day. Only hens laying four or more eggs in an ovulatory sequence with a 1-day pause were used for the experiments. All the hens were hypophysectomized or sham-hypophysectomized 18-20 hr before the estimated time of $\mathrm{a} \mathrm{C}_{3}$ ovulation using the transbuccal approach described by Hill \& Parkes (1934).

\section{Experiment I}

In this experiment, CAP and PMSG were used as the substitutes for LH and FSH respectively, since CAP exhibits properties like those of LH, and PMSG has follicle-stimulating activity.

Eight hours after hypophysectomy the hens were injected i.v. with $4 \mathrm{mg}$ of ovulation-inducing hormone (OIH) preparation of chicken anterior pituitary powder (CAP) or $0.4 \mathrm{mg}$ ovine LH (NIH-LH-S18). After $12 \mathrm{hr}$ the hens were killed and the ovary, oviduct and body cavity were examined for evidence of recent ovulations. The sham-hypophysectomized hens and a group of the hypophysectomized hens served as controls. The hens receiving CAP and ovine LH had previously been injected i.v. with 50-100 i.u. PMSG (Serotropin: Teikokuzoki) and 0.4 mg ovine FSH (NIH-FSH S9), respectively. In one series of experiments the interval between the OIH and PMSG or FSH injections was $6 \mathrm{hr}$ and in another series the interval was $30 \mathrm{~min}$.

All sham-operated hens injected with the OIH (CAP or ovine LH) alone $8 \mathrm{hr}$ after the operation ovulated a single ovum, but many of the hypophysectomized hens ovulated 2 or 3 ova (Table 1). More triple ovulations were induced by $\mathrm{LH}$ than by CAP, probably because the latter is only a crude preparation contaminated with other hormones. When ovine FSH or PMSG were given to the hypophysectomized hens $6 \mathrm{hr}$ before the OIH injection, the multiple ovulations induced were fewer than expected (Table 1). All the hens ovulated 2 or 3 ova, however, when the PMSG or ovine FSH was administered only $30 \mathrm{~min}$ before the $\mathrm{OIH}$ injection.

\section{Experiment II}

This experiment was conducted to determine when after hypophysectomy an FSH injection was able to inhibit the multiple ovulation induced by exogenous $\mathrm{LH}$. 
Table 1. Inhibitory effect of PMSG or FSH treatment on the multiple ovulation induced by injection of an ovulationinducing hormone in hypophysectomized hens

\begin{tabular}{|c|c|c|c|c|c|c|}
\hline \multirow[b]{3}{*}{ Treatment } & \multicolumn{2}{|c|}{ Hours after operation } & \multirow[b]{3}{*}{ No. of hens } & \multirow{2}{*}{\multicolumn{3}{|c|}{ No. of ovulations* }} \\
\hline & \multirow{2}{*}{$\begin{array}{c}\text { PMSG or } \\
\text { FSH } \\
\text { injection }\end{array}$} & \multirow{2}{*}{$\begin{array}{c}\text { CAP or } \\
\text { LH } \\
\text { injection }\end{array}$} & & & & \\
\hline & & & & Single & Double & Triple \\
\hline \multicolumn{7}{|l|}{ Experiment I } \\
\hline \multicolumn{7}{|l|}{ Sham-operated controls } \\
\hline $4 \mathrm{mg} \mathrm{CAP}$ & & 8 & 5 & 5 & & \\
\hline $0.4 \mathrm{mg} \mathrm{LH}$ & & 8 & 11 & 11 & & \\
\hline \multicolumn{7}{|l|}{ Hypophysectomized } \\
\hline $4 \mathrm{mg} \mathrm{CAP}$ (controls) & & 8 & 11 & 5 & 5 & 1 \\
\hline $0.4 \mathrm{mg} \mathrm{LH}$ (controls) & & 8 & 7 & & 3 & 4 \\
\hline 50 i.u. $\mathrm{PMSG}+4 \mathrm{mg} \mathrm{CAP}$ & 2 & 8 & 5 & 5 & & \\
\hline 100 i.u. PMSG $+4 \mathrm{mg}$ CAP & 2 & 8 & 7 & 7 & & \\
\hline 50 i.u. $\mathrm{PMSG}+4 \mathrm{mg}$ CAP & 7.5 & 8 & 4 & & 4 & \\
\hline $0.4 \mathrm{mg} \mathrm{FSH}+0.4 \mathrm{mg} \mathrm{LH}$ & 2 & 8 & 9 & 4 & 5 & \\
\hline $0.4 \mathrm{mg} \mathrm{FSH}+0.4 \mathrm{mg} \mathrm{LH}$ & $7 \cdot 5$ & 8 & 8 & & 6 & 2 \\
\hline \multicolumn{7}{|l|}{ Experiment II } \\
\hline \multirow{5}{*}{$\begin{array}{l}\text { Hypophysectomized } \\
0.4 \mathrm{mg} \mathrm{LH} \text { (controls) }\end{array}$} & & & & & & \\
\hline & & 8 & 4 & & 4 & \\
\hline & 2 & 8 & 3 & 3 & & \\
\hline & 3 & 8 & 6 & 6 & & \\
\hline & 4 & 8 & 7 & 7 & & \\
\hline \multirow{4}{*}{$0.4 \mathrm{mg} \mathrm{FSH}+0.4 \mathrm{mg} \mathrm{LH}$} & 5 & 8 & 7 & 6 & 1 & \\
\hline & 6 & 8 & 6 & 2 & 4 & \\
\hline & 7 & 8 & 4 & & 4 & \\
\hline & $7 \cdot 5$ & 8 & 3 & & 3 & \\
\hline
\end{tabular}

* All the hens were killed $12 \mathrm{hr}$ after the OIH injection.

Hypophysectomized hens were injected with 0.4 mg ovine FSH at $2,3,4,5,6,7$ or $7 \cdot 5 \mathrm{hr}$, and with $0.4 \mathrm{mg}$ ovine $\mathrm{LH}$ at $8 \mathrm{hr}$ after the operation. Hens injected with LH only served as controls. Evidence for recent ovulations was sought as described in Exp. I at $12 \mathrm{hr}$ after the LH injection.

All the control hens injected with LH alone ovulated 2 ova. When FSH was administered 3-6 hr before the LH injection, nearly all the hens had only one ovulation (Table 1). FSH injection $2 \mathrm{hr}$ before the $\mathrm{LH}$ dose resulted in single or double ovulation, but further reduction of the time between FSH and LH did not cause inhibition of multiple ovulation.

\section{Discussion}

There have been many reports that FSH plays an important role concerning ovulation in the hens (Fraps \& Riley, 1942; Ferrando \& Nalbandov, 1969; Kamiyoshi \& Tanaka, 1969; Imai \& Nalbandov, 1971; Kamiyoshi \& Tanaka, 1972). Fraps \& Riley (1942) reported that consecutive administrations of FSH caused an interruption of the natural ovulation sequence in intact hens. The present study also confirmed that FSH may suppress the ovulatory process, because in the hypophysectomized hens the expected multiple ovulation which is induced by exogenous $\mathrm{OIH}$ was inhibited by a single treatment with FSH. This inhibitory effect of FSH must be exerted directly on the follicles, since the hens were hypophysectomized, but an explanation must be sought as to why the FSH injection less than $2 \mathrm{hr}$ before the LH injection did not inhibit the multiple ovulation, and why ovulation of the primary follicle was not inhibited. It is possible that the sensitivity of follicles to OIH increases as the follicles grow, and that the first, second and third follicles of the sequence are therefore more insensitive to FSH when it is available for only a short period before the OIH injection. Administration of FSH 3-6 hr before the OIH dose gives an interval sufficient for 
all except the primary follicle to be affected. Another explanation might be related to the ratio between FSH and OIH concentrations. Though the detailed mechanism of the action of FSH in the ovulatory process remains unclarified, the results of the present study do seem to support the theory of Nalbandov (1961) that ovulation in the hen is normally due to withdrawal of FSH from the mature follicle.

We thank the National Institutes of Health, Bethesda, U.S.A. for the gifts of ovine FSH and LH.

\section{References}

Ferrando, G. \& Nalbandov, A.V. (1969) Direct effect on the ovary of the adrenergic blocking drug dibenzyline. Endocrinology 85, 38-42.

Fraps, R.M. \& Rilex, G.M. (1942) Hormone-induced ovulation in domestic fowl. Proc. Soc. exp. Biol. Med. 49, 253-257.

Hill, R.T. \& Parkes, A. S. (1934) Hypophysectomy of birds. I-Technique, with a note on results. Proc. R. Soc. B 115, 402-409.

ImaI, K. \& Nalbandov, A.V. (1971) Changes in FSH activity of anterior pituitary glands and of blood plasma during the laying cycle of the hen. Endocrinology 88, 1465-1470.
Kamiyoshi, M. \& Tanaka, K. (1969) Changes in pituitary FSH concentrations during an ovulatory cycle of the hen. Poult. Sci. 48, 2025-2032.

KamiYoshi, M. \& TANaKa, K. (1972) Augmentative effect of FSH on LH-induced ovulation in the hen. J. Reprod. Fert. 29, 141-143.

NaLbandov, A.V. (1961) Mechanisms controlling ovulation of avian and mammalian follicles. In Control of Ovulation, pp. 122-132. Ed. C. A. Villee. Pergamon Press, New York.

Opel, H. \& Nalbandov, A.V. (1961) Ovulability of ovarian follicles in the hypophysectomized hen. Endocrinology 69, 1029-1035.

Received 5 January 1976 